\title{
Contemporary skull development - palatal angle analysis
}

\author{
Dostalova $\mathrm{T}^{1}$, Eliasova $\mathrm{H}^{2}$, Gabcova $\mathrm{D}^{1}$, Feberova $\mathrm{J}^{3}$, Kaminek $\mathrm{M}^{4}$ \\ Department of Stomatology, 2nd Medical Faculty, Charles University in Prague and Faculty Hospital in Motol, \\ Prague, Czech Republic. tatjana.dostalova@fnmotol.cz
}

\begin{abstract}
Objectives:The palatal angle is an important angle of the craniofacial complex. It is significant for the diagnosis of craniofacial disorders mainly for nasopharyngeal soft-tissue patterns.

Background The dentists and otorhinolaryngologists use this relationship to establish proper treatment mechanics and evaluate facial profile. The aims of this study were to provide comparative cephalometric analyses of historical and contemporary skulls.

Materials and method:A total of 190 cephalograms of 2 groups of subjects were evaluated. Dolphin Imaging 11.0 - Cephalometric Tracing Analysis was used for the analysis. Unpaired two-tailed t-test assuming equality of variances was used for all variables (at the significance level $p=0.0001$ ).

Results: The modern forensic skulls had larger palatal angle at average value of 8.60 degrees \pm 4.35 , than that of archeological ones, the average value of which was 6.50 degrees \pm 3.92 . The difference was found significant. Unpaired two-tailed t-test assuming equality of variances showed that historical and contemporary skulls had statistically significant results. The difference was -2.09 with standard error of 0.60 (95\% confidence interval from -3.29 to -0.89 ). Two-tailed probability attained value of $P$ was less than 0.0001 .

Conclusion: The difference between both groups was found significant. An increase in the palatal angle can be directly connected with anterior rotation of upper jaw(Tab. 2, Fig. 5, Ref. 19). Text in PDF www.elis.sk. Key words: dentistry, otorhinolaryngology, craniofacial complex, cephalometric radiograph, palatal angle analysis.
\end{abstract}

\section{Introduction}

The maxilla develops postnatally entirely by intramembranous ossification. Since there is no cartilage replacement, the growth occurs in two ways, namely by apposition of bone at the sutures that connect the maxilla to the cranium and cranial base, and by surface remodeling. Maxilla grows downward and forward, which is allowed by the ideally situated sutures attaching the maxilla posteriorly and superiorly and by growth of the cranial base behind it. The growth pattern of the maxilla has been described by Björk in 1955 (1). He used metallic implants in the right side of each arch to analyze growth mechanism of individual human bones on the basis of comparison with the external bone contours. The growth in length is sutural towards the palatine bone. The space at the sutures is filled in by proliferation of bone. The sutures retain the same width, and various processes of the maxilla become longer. This is accompanied by periostal apposition at the maxillary tuberosity, as

${ }^{1}$ Department of Stomatology, 2nd Medical Faculty, Charles University in Prague and Faculty Hospital in Motol, Prague, Czech Republic, ${ }^{2}$ Department of Anthropology and Biology, Institute of Criminalistics Prague, Prague, Czech Republic, ${ }^{3}$ Department of Scientific Information, 2nd Faculty of Medicine, Charles University in Prague, Prague, Czech Republic, and ${ }^{4}$ Orthodontic Department, Stomatology Clinic, Medical Faculty of Palackeho University, Olomouc, Czech Republic

Address for correspondence:T.Dostalova, MD, PhD, DSc, MBA, Department of Stomatology, Charles University, 2nd Medical Faculty, V Uvalu 84, CZ-150 06 Prague 5,,Czech Republic.

Phone: +420.728970059

Acknowledgments: This project has been supported by Grant No. NT 13351-4 MZCR, 00064203 (FN MOTOL), and project VF 20102014007. a free surface. Bone addition creates additional space into which the primary and then the permanent molar teeth successively erupt. The growth in length has not been found on the anterior surface of the maxilla, apart from the alveolar process, as almost the entire anterior surface of the maxilla is an area of resorption, not apposition.

The growth in height takes place at the sutural articulations of the frontal and zygomatic processes, and by periostal apposition on the lower border of the alveolarprocess. Thenasal floor is lowered through resorption together with periostal apposition on the hard palate, and the anterior nasal spine is likewise lowered through resorptive remodeling. The overall growth changes result from both downward and forward translation of the maxilla and simultaneous surface remodeling. The whole bony nasomaxillary complex is moving downward and forward relative to the cranium, being translated in space (2-6).

The knowledge of growth changes and possibility of their influence have fundamental significance for the treatment of orthodontic anomalies. As a research tool, cephalometry has been the most widely used imaging modality in orthodontic investigations. Cephalometry has been used to quantify craniofacial parameters in individuals or sample population, distinguish normal from abnormal anatomy, compare treated and untreated sample populations, differentiate homogeneous from mixed populations, and to assess patterns of change through time.

Palatal angle is one of values which serve to determine whether upper jaw rotates more intensively forward and down or vice versa. To determine this angle we use upper palatal plane which is a connection of two points, namely anterior nasal spine (ANS) and posterior nasal spine (PNS) as well as anterior cranial base which is also a connection of two points, namely Sella (S) and Nasion 
Tab. 1.Palatal angle - current orthodontic analysis.

\begin{tabular}{|c|c|c|c|}
\hline SN- Palatal plane & & & \\
\hline Analysis & Mean & SD & Reference \\
\hline Bell, Proffit and White & 7 & \pm 3 & Athanasios E. Athanasiou: Orthodontic cephalometry. Mosby-Wolfe, 1995. \\
\hline Bjork-Cranio-Mx Base/SN-Palatal Plane $\left(^{\circ}\right)$ & 7.3 & 3.5 & $\begin{array}{l}\text { Dolphin user guide manual 6.0, Dolphin Computer Access www.DolphinGuide.com } \\
\text { (2012). }\end{array}$ \\
\hline $\begin{array}{l}\text { SN-PP Class I } \\
\text { male } \\
\text { female }\end{array}$ & $\begin{array}{l}8.97 \\
9.38 \\
8.57\end{array}$ & $\begin{array}{l} \pm 3.05 \\
\pm 3.43 \\
\pm 2.57\end{array}$ & $\begin{array}{l}\text { Hiroshi Iwasaki, Hiroyuki Ishikawa, Lamiya Chowdhury, Shinji Nakamura, and Ju- } \\
\text { nichiro Iida. Properties of the ANB angle and the Wits appraisal in the skeletal esti- } \\
\text { mation of Angle's Class III patients Eur J Orthod 2002; 24(5): 477-483. }\end{array}$ \\
\hline $\begin{array}{l}\text { SN-PP Class III } \\
\text { male } \\
\text { female }\end{array}$ & $\begin{array}{c}9.91 \\
10.29 \\
9.67\end{array}$ & $\begin{array}{l} \pm 3.01 \\
\pm 3.06 \\
\pm 2.96\end{array}$ & $\begin{array}{l}\text { Hiroshi Iwasaki, Hiroyuki Ishikawa, Lamiya Chowdhury, Shinji Nakamura, and Ju- } \\
\text { nichiro Iida. Properties of the ANB angle and the Wits appraisal in the skeletal esti- } \\
\text { mation of Angle's Class III patients Eur J Orthod2002; 24(5): 477-483. }\end{array}$ \\
\hline $\begin{array}{l}\text { Vertical Cephalometric Analysis } \\
\text { (Vertical cephalometric analysis is a calibrat }\end{array}$ & d meth & \pm 2 & $\begin{array}{l}\text { Alió-Sanz JJ. A new cephalometric diagnostic method for Down's Syndrome patients } \\
\text { with open bite. Med Oral Patol Oral Cir Bucal 2008;13(3):E171-175. } \\
\text { y for the differential diagnosis of skeletal and dentoalveolar open bites.) }\end{array}$ \\
\hline $\begin{array}{l}\mathrm{SN}-\mathrm{PP}\left({ }^{\circ}\right) \\
\text { control group } \\
\text { treated group }\end{array}$ & $\begin{array}{l}8.62 \\
9.95\end{array}$ & $\begin{array}{l}2.98 \\
3.76\end{array}$ & $\begin{array}{l}\text { Cozza P, Giancotti A, Petrosino A. Rapid palatal expansion in mixed dentition using } \\
\text { a modified expander: a cephalometric investigation. J Orthod 2001;28(2):129-134. }\end{array}$ \\
\hline $\begin{array}{l}\text { SN-PP } \\
\text { before treatment } \\
\text { after treatment }\end{array}$ & $\begin{array}{l}6.88 \\
6.79\end{array}$ & $\begin{array}{l}2.72 \\
2.80\end{array}$ & $\begin{array}{l}\text { PINTO, Francisco Marcelo Paranhos et al. Vertical growth control during maxillary } \\
\text { expansion using a bonded Hyrax appliance. Dental Press J Orthod [online]. 2012, } \\
\text { vol.17, n.1 [cited 2013-02-25], pp. 101-107. }\end{array}$ \\
\hline $\begin{array}{l}\text { SN-PP } \\
\text { Class I } \\
\text { Class II } \\
\text { Class III } \\
\text { Open bite }\end{array}$ & $\begin{array}{l}6.8 \\
5.8 \\
7.5 \\
6\end{array}$ & $\begin{array}{l}3.7 \\
3.2 \\
7.3 \\
5.2\end{array}$ & $\begin{array}{l}\text { Celar AG, Freudenthaler JW, Celar RW, Jonke E, Schneider B. The denture frame } \\
\text { analysis: an additional diagnostic tool Eur J Orthod1998; 20(5): 579-587. }\end{array}$ \\
\hline
\end{tabular}

(No statistical difference was found between the groups i the angle SN-PP.)

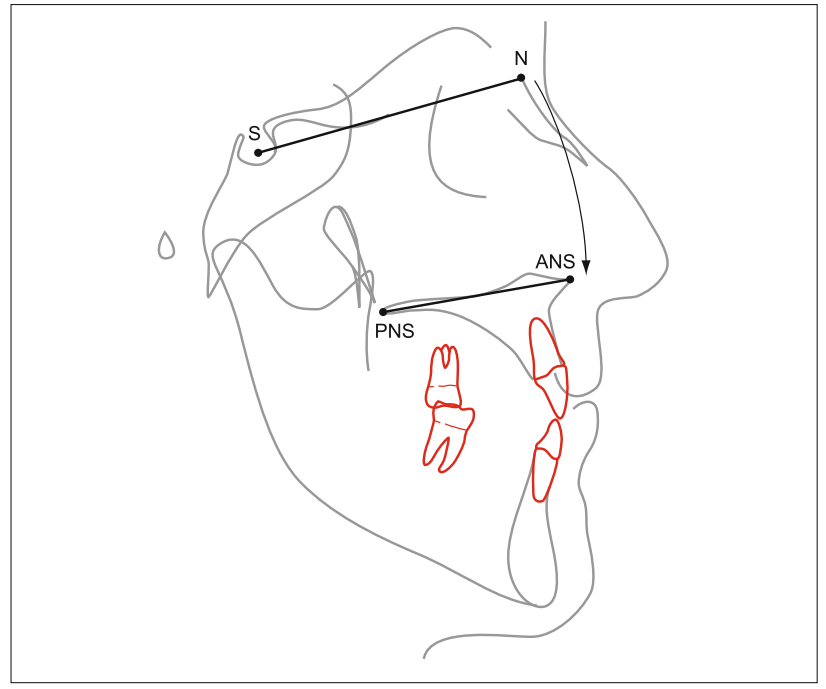

Fig. 1.Anterior cranial base (N-S line); palatal plane (ANS-PNS line).

(N) on cephalometry (Tab. 1, Fig. 1). The normal value of palatal angle for European population is about $8.1^{\circ}(7)$. Deviation grows significantly forward and down and the angle shows the degrees of declination of the maxilla to the cranial base.

The importance of correct identification of the anteroposterior jaw relationship is essential. The clinician uses this relationship to establish detailed treatment goals and proper treatment mechanics. It has often been observed that the intermolar relationship is not necessarily related to the facial profile. When analyzing cephalometrics, many patients with Class I molar relationship show an obvious Class II or Class III pattern in their facial profile. Most of these cases show abnormal rotation of the jaws relative to cranial anatomy (8-11).

The horizontal relationship of denture bases can be defined using the angles or distances between reference planes of the craniofacial complex and points $A$ and $B$, which are representative of the anterior limits of denture bases. The skeletal A-P relationship is probably affected by the vertical jaw relationship. In other words, the degree of A-P relationship can vary in response to a vertical change in facial dimension (5). Accordingly, it might be said that the skeletal sagital aspect could be described more adequately by angles between craniofacial reference planes and A-B plane, which is supplemented by a consideration of both vertical and horizontal distances between points A and B, concurrently.

Therefore, the aims of this study were 1 ) to examine statistically and geometrically the different cephalometric measurements which are used to indicate $\mathrm{SN}$ - palatal planerelationship, and 2) to providecomparative cephalometric analysis of historical and contemporary forensic skulls.

\section{Material and methods}

Palatal angle size and relationship of the angle size in modern (forensic) and archeological skulls were investigated in this study. A total of 190 cephalograms of 2 groups of subjects, namely forensic (75 unknown individuals; 67 men and 8 women from Institute of Criminalistics, Prague, Czech Republic) and archeological subjects (115 skulls dated 8th-12th century; excavations of Slavic settlements in Czech and Moravian regions), were evaluated. The lateral cephalograms were taken under standard conditions. The sensor-focus distance from the median plane of the patient's head 


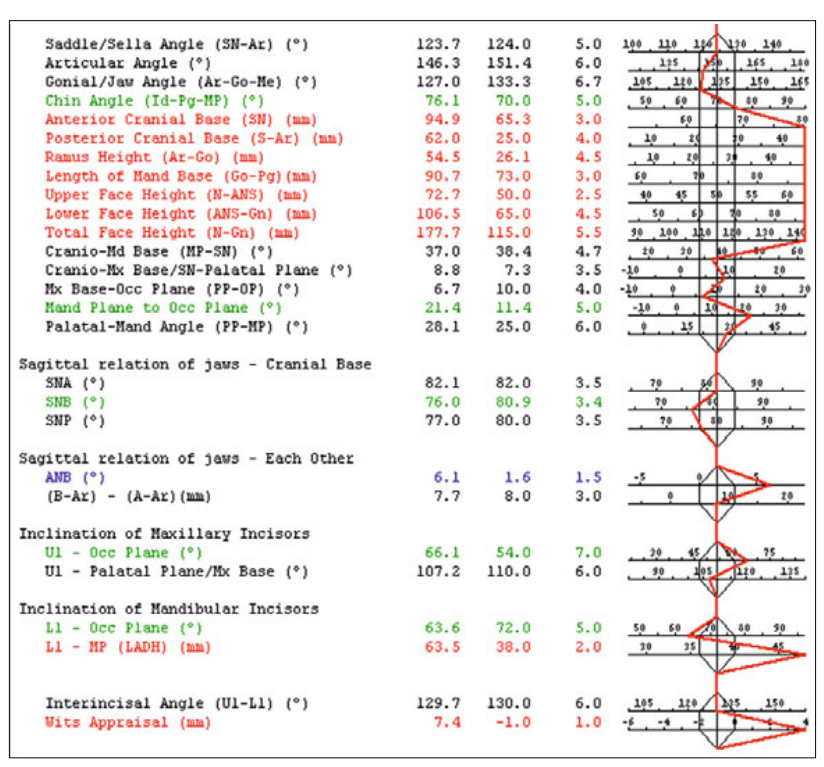

Fig. 2. Dolphin Imaging 11.0 - current forensic skull cephalometric analysis.

was $150 \mathrm{~cm}$, and the median plane-sensor distance was $10 \mathrm{~cm}$. The cephalograms of contemporary group were taken with the subjects standing with the head positioned in the cephalostat and orientated to the Frankfort horizontal plane parallel to the underlay. To minimize error, all measurements were made by the same person.

Dolphin Imaging 11.0 - Cephalometric Tracing Analysis (CephX Inc. Las Vegas, NV) was used for the analysis (Figs 2 and 3).

All subjects were of Caucasian origin and therefore ethnically represented a very homogeneous group. All cephalometric radiographs of these subjects were made with the same panoramic machine (Gendex, Oralix 9200, Milan, Italy). Cephalometric Tracing Analysis was performed by two orthodontists (Fig. 4).

\section{Statistical evaluation}

The subjects were divided into 2 groups (75 contemporary forensic skulls, 115 archeological samples) to compare the palatal angle differences. Unpaired two-tailed t-test assuming equality of variances was used for all variables (at the significance level $\mathrm{p}=0.0001)$.

\section{Results}

The modern forensic skulls had larger average palatal angle value, namely 8.60 degrees \pm 4.35 , than the archeological ones, the average value of which was 6.50 degrees \pm 3.92 . The difference was found significant. Unpaired two-tailed t-test assuming equality of variances showed that forensic and archeological skulls had statistically significant results. The difference was -2.09 with standard error of 0.60 (95 \% confidence interval from -3.29 to -0.89). Twotailed probability attained the value of P less than 0.0001 (Tab. 2).

The significant difference existed in measurements of the palatal angle between forensic and archeological dentate groups. We were able to confirm discrepancies in shape of maxilla including box plot in interval (Fig. 5).

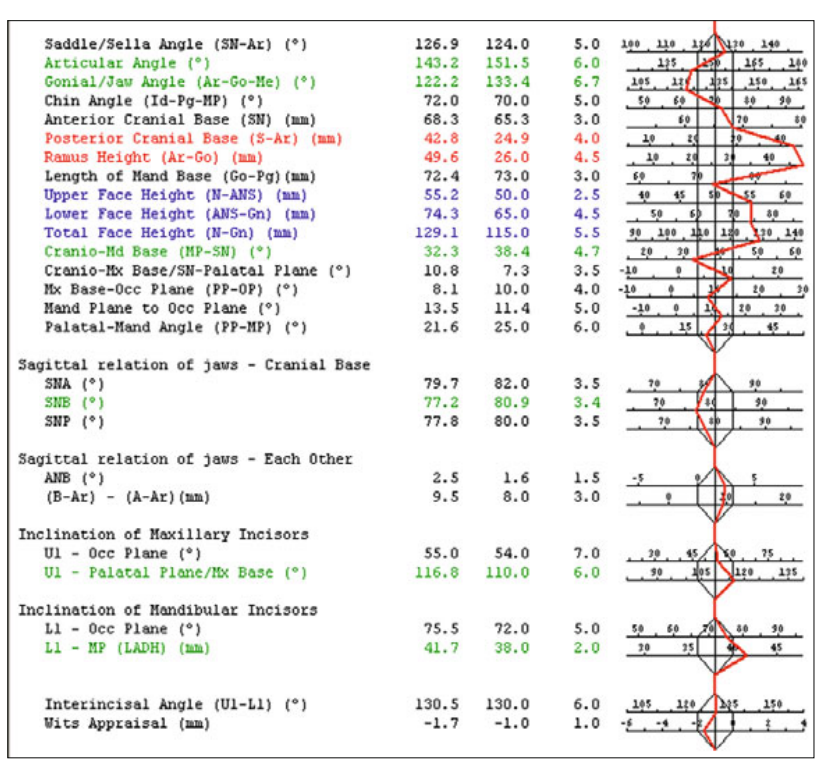

Fig. 3. Dolphin Imaging 11.0 - archeological skull cephalometric analysis.

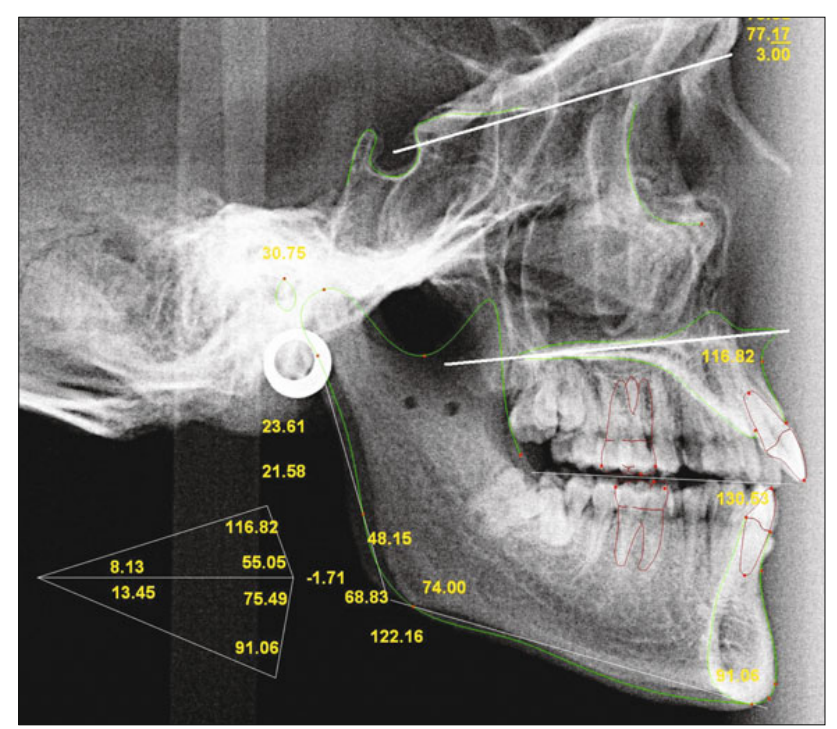

Fig. 4. Dolphin Imaging 11.0 - Cephalometric Tracing Analysis - palatal angle.

A comparison of the mean data for the two groups indicates that the mean palatal angle for the forensic skulls was 8.60 degrees (with a variance of 18.96) in comparison to the archeological skulls whose mean palatal angle was 6.50 degrees (with a lower variance of 15.36).

Tab. 2.Palatal angle evaluation.

\begin{tabular}{lcc}
\hline & \multicolumn{2}{c}{ Palatal angle } \\
\cline { 2 - 4 } & Modern (forensic) sculls & Archeological sculls \\
\hline $\mathrm{N}$ & 75 & 115 \\
\hline Mean & 8.6 & 6.5 \\
\hline $95 \% \mathrm{Cl}$ & 7.6 to 9.6 & 5.8 to 7.2 \\
\hline SD & 4.4 & 3.9 \\
\hline F-test & \multicolumn{3}{l}{} \\
\hline T test (two tailed probability) & $\mathrm{p}=0.0007$ \\
\hline
\end{tabular}




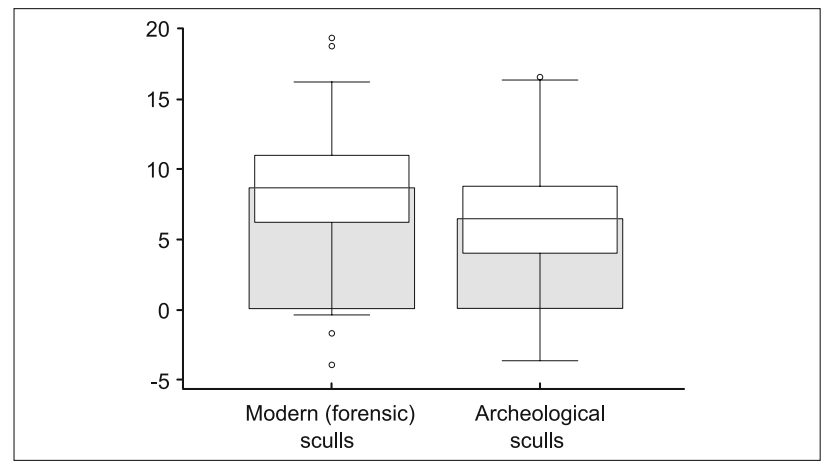

Fig. 5.Palatal angle analysis - statistical evaluation.

As the Pvalue for the analysis was less than 0.0001 , we can conclude that the hypothesis of different palatal angle is statistically significant. From the measurements, we have shown that the type of life style had direct influence on anatomy of skull in the palatal angle area.

When the results were compared with contemporary orthodontic cephalometric analysis (Tab. 1) it was evident that all mentioned groups excluding children $(12,13)$ had also higher palatal angle, namely from 7.00 to 10.29 degrees.

\section{Discussion}

The palatal angle is an important angle of the craniofacial complex. It is significant for the diagnosis of craniofacial disorders mainly for nasopharyngeal soft-tissue patterns. Nasal fossa, cranial base, and adenoidal tissue were larger in men. All variables except lower pharynx dimension were statistically related. Great dependence was observed between some variables, namely the upper airway thickness explained $60 \%$ of the changes in upper pharyngeal dimension and $67 \%$ of changes in aerial area. Cranial base length was related to different variables defining the airway, mainly nasal fossa length and lower airway thickness. Palatal angle was statistically correlated with upper airway area (14) and this space has direct influence on obstructive sleep apnea (15). Also cleft patient ANB angle was the most significant predictor for later osteotomy. Despite individual variation, all children $(\mathrm{n}=13)$ whose ANB angle was less than $7^{\circ}$, needed later orthognathic surgery; whereas, none of those whose ANB angle was greater than $12.5^{\circ}(\mathrm{n}=6)$ needed maxillary osteotomies (16).

Lateral cephalogram or three-dimensional cone beam computed tomography can be usually used to determine this angle (17). Smith (18) found that computerized cephalometric analysis yields comparable results to traditional cephalometric analysis, but can be used also for skulls.Cephalometric tracing analysis helped us capture standardized images and achieve precise measurement.

Genetic drift is rejected as a predominant mechanism influencing the maxilla shape in Homo sapiens (19). Our results confirmed that palatal angle size is also connected with assessing the morphology of the maxilla and had direct influence on upper jaw development. We found a significant difference between the archeological and forensic groups. An increase in the palatal angle can be directly connected with less marked anterior rotation of upper jaw. Also this result was statistically significant.
The considerable transformative changes in the palatal angle may be attributed to several factors, and it is known that the maxilla does not follow one characteristic pattern throughout the development. The present study concludes that during the development, there seems to be a significant difference in the palatal angle. At present, the palatal angle shows to be definitely increased.

\section{References}

1. Björk A. Facial growth in man, studied with the aid of metallic implants. ActaOdontolScand 1955; 13 (1): 9-34.

2. Björk A. Sutural Growth of the Upper Face Studied by the Implant Method. ActaOdontolScand 1966; 24 (2): 109-127.

3. Björk A, Skieller V. Growth of the maxilla in three dimensions as revealed radiographically by the implant method. Br J Orthod 1977; 4 (2): 53-64.

4. Ochoa BK, Nanda RS. Comparison of maxillary and mandibular growth. Am JOrthodDentofacOrthop. 2004; 125 (2): 148-159.

5. Proffit WR, Fields H W, Sarver DM. Contemporary Orthodontics. St. Louis, Mo: Mosby Elsevier. 2007.

6. Yang SD, Suhr CHH. F-H to AB plane (FABA) for assessment of anterioposterior jaw relationship. Angle Orthod 1995; 65 (3): 223-232.

7. Hasund A, Stenger D. Individualizovanákefalometrie, Prague,1994.

8. Alió-Sanz JJ. A new cephalometric diagnostic method for Down's syndrome patients with open bite. Med Oral Patol Oral Cir Bucal 2008:13 (3);E171-175.

9. Cozza P, Giancotti A, Petrosino A. Rapid palatal expansion in mixed dentition using a modified expander: a cephalometric investigation. J Orthod 2001; 28 (2): 129-134.

10. Dolphin guide user manual 6.0, Dolphin Computer Accesswww.DolphinGuide.com.2012

11. Iwasaki H, Ishikawa HI, Chowdhury L, Nakamura S, Iida J. Properties of the ANB angle and the Wits appraisal in the skeletal estimation of Angle's Class III patients.Eur J Orthod 2002; 24 (5): 477-483.

12. Celar AG, Freudenthaler JW, Celar RM, Jonke E, and Schneider B. The denture frame analysis: an additional diagnostic tool. Eur J Orthod 1998; 20 (5): 579-587.

13. Pinto FMP. Vertical growth control during maxillary expansion using a bonded Hyrax appliance. Dental Press J Orthod 2012; 17 (1): 101-107.

14. Martin O, Muelas L, Viñas MJ. Nasopharyngeal cephalometric study of ideal occlusions.Am J OrthodDentofacialOrthop 2006; 130 (4): 436e1-9.

15. Heliövaara A, Leikola J, Hukki J.Craniofacial cephalometric morphology and later need for orthognathic surgery in 6-year-old children with bilateral cleft lip and palate. Cleft Palate Craniofac J 2013; 50 (2): e35-40.

16. Guijarro-Martínez R, Swennen GR. Three-dimensional cone beam computed tomography definition of the anatomical subregions of the upper airway: a validation study. Int J Oral MaxillofacSurg 2013Apr 25. pii: S09015027(13)00117-3. doi: 10.1016/j.ijom.2013.03.007. [Epub ahead of print]

17. Erkan M, Gurel HG, NurM .Reliability of four different computerized cephalometric analysis programs. Eur J Orthod 2012; 34 (3): 318-321.

18. Smith HF. The role of genetic drift in shaping modern human cranial evolution: a test using microevolutionary modeling. Int J EvolBiol 2011; 145-262.

19. Ping-Ying Chiang R, Lin CM, Powell N, Chiang YC, Tsai YJ.Systematic analysis of cephalometry in obstructive sleep apnea in Asian children. Laryngoscope2012; 122 (8): 1867-1872.

Received November 26, 2013. Accepted December 12, 2013. 